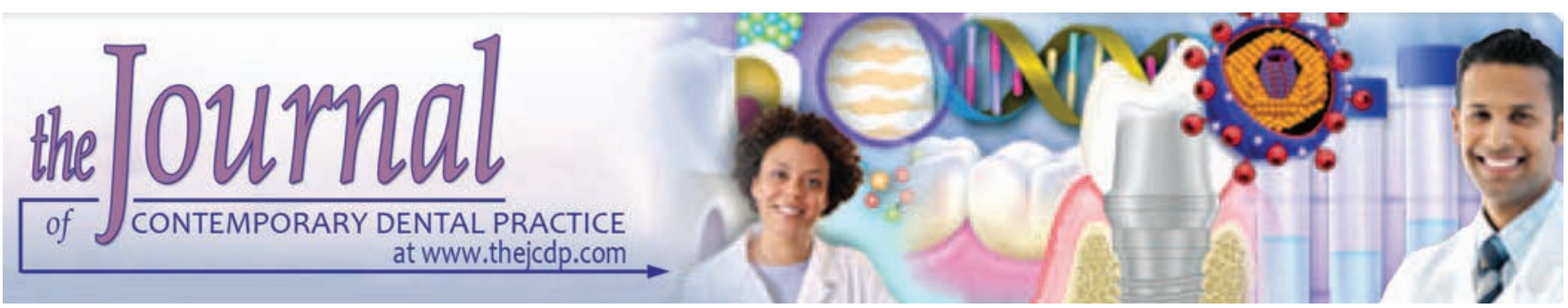

\title{
Risk Factors and Treatment Needs among Orphan School Children
}

\author{
${ }^{1}$ Malleedi Shanthi, ${ }^{2}$ EV Soma Sekhar Goud, ${ }^{3} \mathrm{G}$ Padmanabha Kumar, ${ }^{4}$ Jagdeesh P Rajguru \\ ${ }^{5}$ Subramaniam Ratnasothy, ${ }^{6} \mathrm{Kranti}$ KR Ealla
}

\begin{abstract}
Aim: The aim of the study was to identify risk factors and treatment needs of orphan children of Selangor, Kuala Lumpur, Malaysia.

Objectives: (1) To identify the association between the frequency of snacking and caries among orphan schoolchildren, (2) To assess Streptococcus mutans and Lactobacilli (microbiological assessment) in saliva of orphan children, and (3) To formulate treatment needs for orphan children.
\end{abstract}

Materials and methods: A cross-sectional study was done among 253 children of 5-, 12-, and 15-year-olds living in various orphanage houses of Selangor, Kuala Lumpur, Malaysia. Demographic data, and dietary and oral hygiene practices were collected through a structured questionnaire. Clinical examinations of children were conducted to assess oral health status and recorded in the World Health Organization oral health assessment form (1997). Stimulated saliva was collected for $S$. mutans and Lactobacilli levels. The statistical software, namely, Statistical Package for the Social Sciences version 19.0 was used for the analysis of the data.

Results: The final data analysis included 253 children of which 116 (45.8\%) were boys and 137 (54.2\%) were girls. Overall,

\footnotetext{
${ }^{1}$ Department of Pediatric Dentistry, MAHSA University, Kuala Lumpur, Malaysia

${ }^{2}$ Department of Oral and Maxillofacial Pathology, MAHSA University, Kuala Lumpur, Malaysia

${ }^{3}$ Department of Oral and Maxillofacial Surgery, MAHSA University, Kuala Lumpur, Malaysia

${ }^{4}$ Department of Oral Pathology and Microbiology, Hi-Tech Dental College \& Hospital, Bhubaneswar, Odisha, India

${ }^{5}$ Department of Family Dentistry, MAHSA University, Kuala Lumpur, Malaysia

${ }^{6}$ Department of Oral and Maxillofacial Pathology, MNR Dental College \& Hospital, Sangareddy, Telangana, India

Corresponding Author: Shanthi M, Department of Pediatric Dentistry, MAHSA University, Kuala Lumpur, Malaysia, e-mail: shanthineha2012@gmail.com
}

140 (55.33\%) children were caries-free and 113 (44.66\%) children presented with caries (decayed/missing/filled surface $>0$ ). High levels of salivary microbiological counts (S. mutans and Lactobacilli), i.e., $\geq 10^{5}$, stress the importance of necessary preventive oral health services. Treatment needs among orphan children showed that most of the children, i.e., 58 (22.9\%), need preventive or caries-arresting care followed by 49 (19.4\%) who require two-surface filling as an immediate measure.

Conclusion: From the results of our study, orphan children have low utilization of preventive and therapeutic oral health services. Urgent attention is required to plan a comprehensive dental health-care program to improve their oral health status.

Clinical significance: Parents are the primary caretakers of children, but woefully some of them have to lead their lives without parents, the latter either being dead or incapable of bringing up their children. Such a group of children is known as orphans. As oral health is an integral part of general health, it is essential for health-care policy makers to address oral health needs of this underprivileged group of society. This article highlights the risk factors and treatment needs among orphan schoolchildren.

Keywords: Dental caries, Oral health, Orphan, Orphanage.

How to cite this article: Shanthi M, Goud EVSS, Kumar GP, Rajguru JP, Ratnasothy S, Ealla KKR. Risk Factors and Treatment Needs among Orphan School Children. J Contemp Dent Pract 2017;18(10):893-898.

Source of support: The study was supported by MAHSA research grant with reference number RP-58-04/14 and we thank for this support.

\section{Conflict of interest: None}

\section{INTRODUCTION}

Oral health is an inseparable part of general health and well-being of an individual. Ideal oral health is defined as a standard of health free from active disease, which enables a person to carry out activities of daily living without discomfort. ${ }^{1}$ Oral diseases are significant health problems around the world. Dental caries and periodontal diseases affect almost $100 \%$ of the population worldwide. ${ }^{2}$ According to the World Health Organization's (WHO's) 
global review of oral health, $90 \%$ of schoolchildren worldwide experienced caries, with the disease being most prevalent in Asian and Latin American countries. ${ }^{3}$ The level of oral diseases in a society is influenced by environment (physical and social), individual's lifestyles, behavior, socioeconomic factors as well as access to health care services. Despite great improvements in oral health with newer technology and materials, the global problem still persists. This is particularly more among underprivileged groups in both developing and developed countries. One of the known high-risk groups is orphans. ${ }^{4}$

According to the United Nations Children's Fund, ${ }^{5}$ there are 153 million orphaned children and adolescents living in the world. As a whole in the continent of Asia, the total orphan population is around 5,72,20,000, accounting for $5.8 \%$ of the total child population. Orphans are the group of children who lead their lives without or unknown parents and live in orphanages. ${ }^{6}$ The pattern of orphanage living is different from family living. Although it provides security, food, and shelter, it is devoid of psychological security. Health problems of these children may be complex due to depression and it may lead to immune suppression and risk for many infections, communicable diseases, and malnutrition. It may relate to living conditions in that particular orphanage that has funding and caretaker problems. Malaysia, a Southeast Asian country, focuses on oral health and lifelong wellness. Oral health care $^{7}$ in Malaysia is provided by both the public and private sectors. With more than $31 \%$ of the Malaysian population being below the age of 20 , oral health care of children continues to be a priority. An improvement in the oral health status by modification of dietary habits and oral hygiene practice is crucial in the prevention of oral diseases. This can be delivered through an incremental approach with focus on prevention, early detection, and control of oral diseases. Although the majority of oral diseases are not life-threatening, the consequences of poor oral health can be severe enough to affect the quality-of-life.

The WHO recommends planning of dental services based on the information collected through surveys about oral diseases, oral health, and treatment needs of a population. ${ }^{8}$ Many studies ${ }^{9,10}$ were done in the past in different groups of children, but evaluation of the same in orphan children is lacking. They form a perfect group for this study. Hence, the present study was undertaken with the aim of identification of risk factors (dietary/ microflora) and treatment needs among orphan schoolchildren of Selangor, Kuala Lumpur, Malaysia.

\section{MATERIALS AND METHODS}

A descriptive, cross-sectional, epidemiological study was designed and undertaken among 253 children aged 5, 12, and 15 years, who are residing at various orphanages of Selangor, Kuala Lumpur, Malaysia.

\section{Inclusion Criteria}

- Orphan children aged 5, 12, and 15 years who were native residents of Malaysia

- Children with informed consent from orphanage authorities

- Children who were willing and cooperative

\section{Exclusion Criteria}

- Children suffering from any systemic disease or handicapped condition

- Children having difficulty in opening the mouth

- Children on medication

Available participants were selected randomly. The study protocol was reviewed and approved by the Research Review Committee, Mahsa University. Informed consent was obtained prior to examination from orphanage officials. A self-administered structured questionnaire was designed in English and regional language to record sociodemographic characteristics (gender, education level, age, and ethnicity), snacking, and oral hygiene habits. The WHO Oral Health Assessment form ${ }^{11}$ was used to record primary and permanent dentition status and treatment needs of the study population. Stimulated saliva was collected from each participant, and microbiological assay was commenced within 24 hours of saliva collection.

\section{Saliva Collection}

The child was instructed not to eat or drink 10 minutes before the saliva collection procedure (Fig. 1). Super SAL ${ }^{\mathrm{TM}}$ saliva collection device was used. The device was placed in the mouth along the side of the tongue until the appearance of the sample volume adequacy indicator changes from light green to blue after 1 to 3 minutes. Saliva from the Super SAL device was transferred to an Eppendorf tube and the lid on the tube was closed tightly. Labeled tubes were transferred to research laboratory for Streptococcus mutans and Lactobacilli count.

\section{Caries Risk Test ${ }^{\circledR}$ Bacteria}

The Caries Risk Test (CRT) bacteria with bright agar surface was used to determine Lactobacilli count and blue agar surface for $S$. mutans count in saliva by means of selective culture media (Fig. 2). Agar carrier is removed from the test vial and $\mathrm{NaHCO}_{3}$ tablet was placed at the bottom of the vial. Both the agar surfaces are wetted by saliva using a pipette after removing the protective foils. The vial was closed and incubated at $37^{\circ} \mathrm{C}$ for 

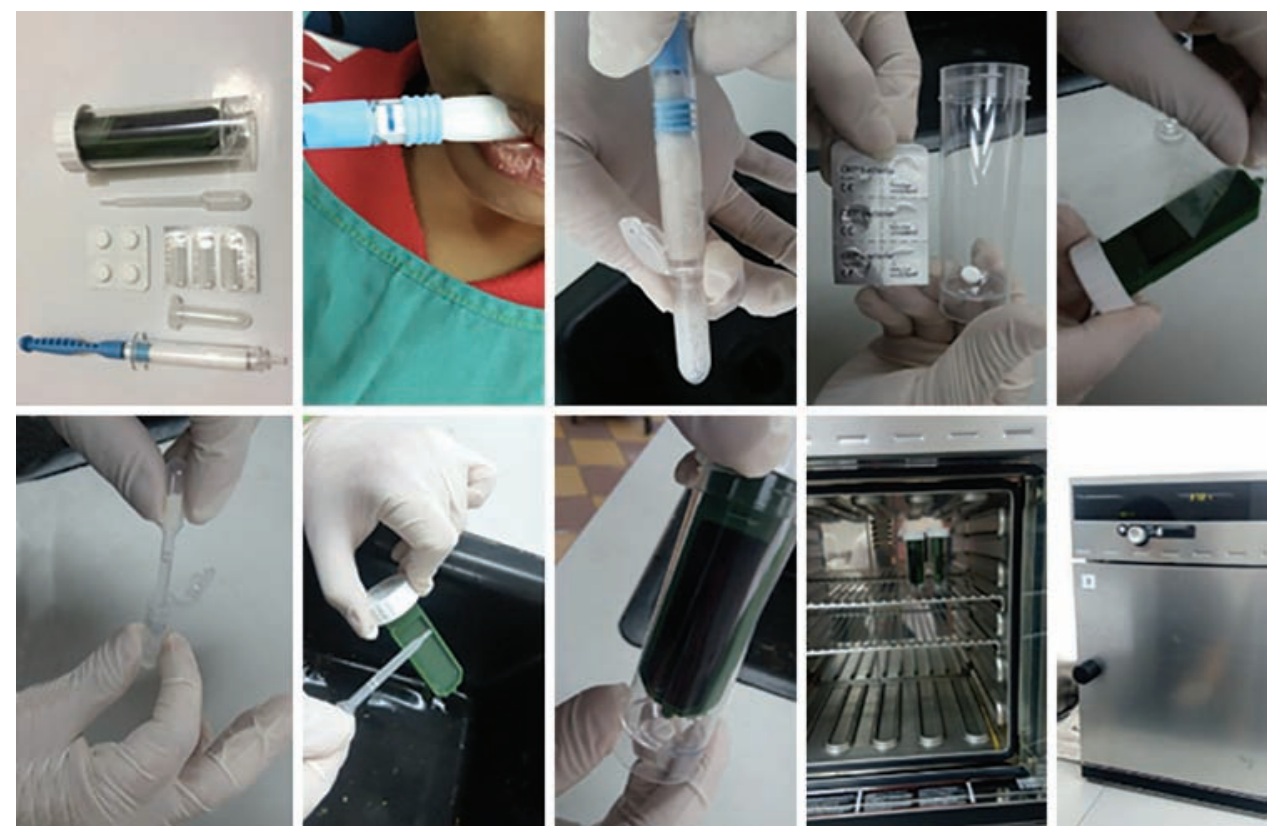

Fig. 1: Saliva collection, coating agar surface, and incubation
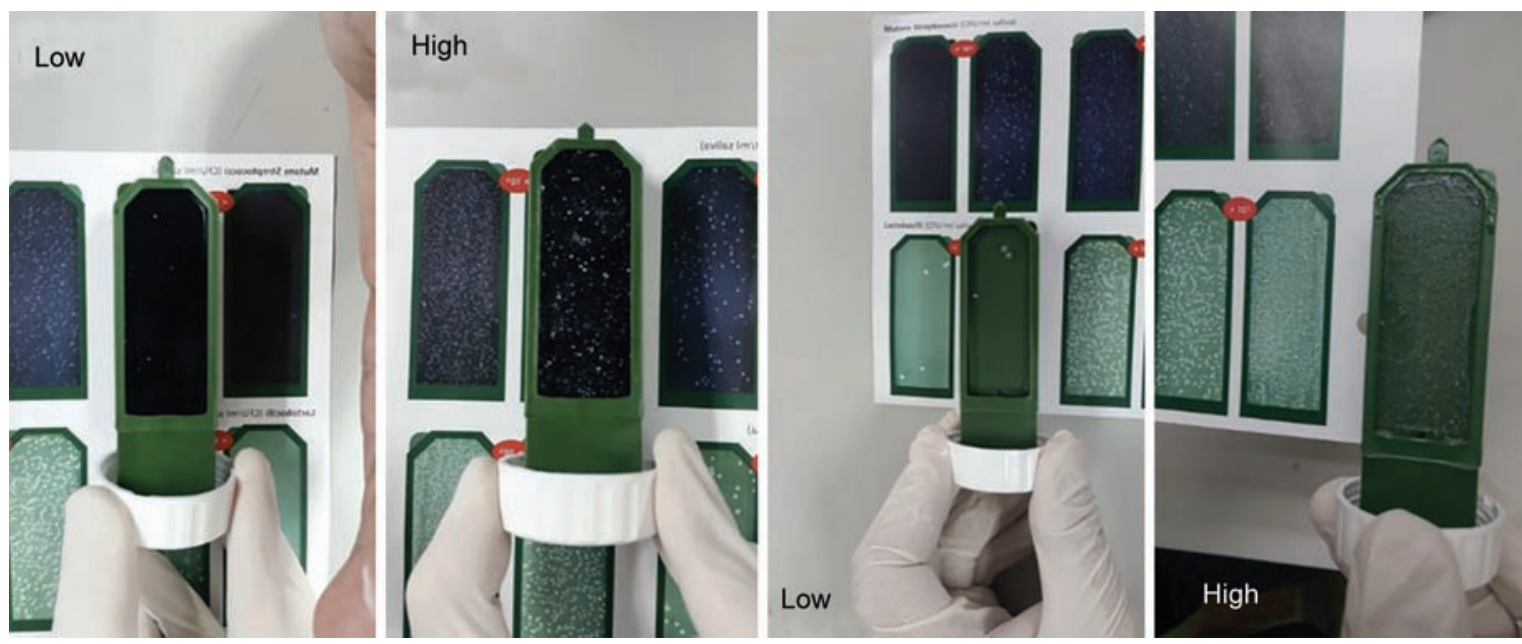

Fig. 2: Streptococcus mutans and Lactobacillus count on agar surface

48 hours. The densities of S. mutans and Lactobacilli colonies were compared and recorded with model chart. The collected baseline data were transferred to a master chart in Microsoft Excel for the purpose of data analysis.

\section{Statistical Analysis}

Qualitative data were presented as frequency and percentage. The Chi-squared test was applied to study the association of treatment needs with various risk factors. The total sample $\mathrm{p}<0.05$ was considered statistically significant.

\section{RESULTS}

A descriptive, cross-sectional study was carried out on a total of 253 children residing in various orphanages of Selangor, Malaysia, out of which, 80 (36 boys and
44 girls) were 5-year-olds, 89 ( 43 boys and 46 girls) were 12 years, and 84 ( 37 boys and 47 girls) were 15 years (Table 1). Based on 24-hour diet assessment, the frequency of snacking was high among these children. All children $(100 \%)$ were reported to eat a snack once or more times in a day, and $41.8 \%$ ate sweet snacks two to three times in between their meal. The proportions of children with

Table 1: Distribution of study population by age and gender

\begin{tabular}{llll}
\hline & Male & Female & Total \\
\cline { 2 - 4 } Age (years) & $n(\%)$ & $n(\%)$ & $n(\%)$ \\
\hline 5 & $36(31)$ & $44(32)$ & $80(31.5)$ \\
10 & $43(37)$ & $46(34)$ & $89(35.5)$ \\
15 & $38(32)$ & $46(34)$ & $84(33)$ \\
Total & $117(100)$ & $136(100)$ & $253(100)$ \\
Mean \pm SD & $10.04 \pm 3.98$ & $10.10 \pm 4.08$ & $10.07 \pm 4.03$ \\
\hline
\end{tabular}

SD: Standard deviation 


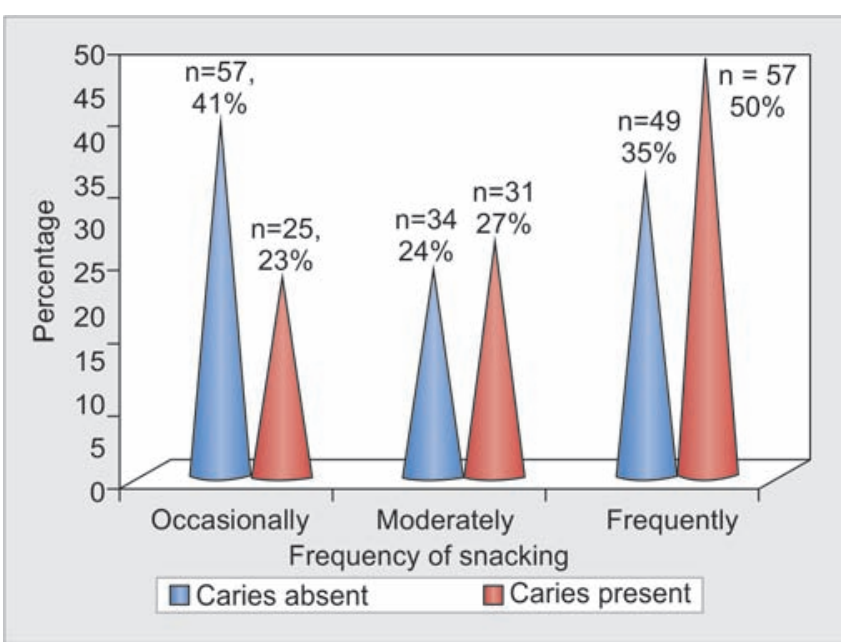

Graph 1: Distribution of the study population according to frequency of snacking and caries. Chi-square -10.468 ; level of significance, $\mathrm{p}=0.005$

caries increased by increasing number of sweet items eaten on most days, and it was statistically significant as shown in Graph 1. Brushing habits of the study population were at least once a day (41.1\%), with 58.9\% twice or more than twice in a day. Although the majority of them brush twice per day, oral hygiene was poor with dental caries and halitosis (Table 2). This may be due to lack of proper brushing technique and supervision. A total of $80.2 \%$ of participants carried detectable salivary levels of $S$. mutans, $38.7 \%$ of these had a score of $<10^{5}$ colony-forming units (CFU) $/ \mathrm{mL}$, and $41.5 \%$ had a score of $\geq 10^{5} \mathrm{CFU} / \mathrm{mL}$. Out of $83.3 \%$ with detectable salivary levels of Lactobacilli, $47 \%$ had a score of $<10^{5} \mathrm{CFU} / \mathrm{mL}$ and $36.3 \%$ a score of $\geq 10^{5} \mathrm{CFU} / \mathrm{mL}$ (Table 3 ). The study population is highly susceptible to caries development due to high levels of salivary microbial counts, which need implementation of preventive programs for them. Treatment needs among study participants showed that $58(22.9 \%)$ needed preventive or caries-arresting care,
Table 2: Presence of dental caries by frequency of brushing

\begin{tabular}{llllr}
\hline & \multicolumn{3}{c}{ Frequency of brushing } & \\
\cline { 2 - 3 } & \multicolumn{3}{c}{ Twice/>twice } & \\
& Once a day & a day & $\chi^{2}$ & $p$-value \\
\hline No carious teeth & $32(30.8 \%)$ & $109(73.2 \%)$ & 44.60 & $<0.001$ \\
Presence of & $72(69.2 \%)$ & $40(26.8 \%)$ & & \\
carious teeth & & & & \\
\hline Level of significance ( $\mathrm{p}$ value) & & & &
\end{tabular}

Table 3: Distribution of study population based on microbial count

\begin{tabular}{lllll}
\hline & Male & Female & & \\
\cline { 2 - 3 } & $n(\%)$ & $n(\%)$ & $\chi^{2}$ & $p$-value \\
\hline $\begin{array}{l}\text { Streptococcus } \\
\text { mutans count }\end{array}$ & & & & \\
$<10^{5}$ & $55(51.4)$ & $43(44.8)$ & 0.885 & 0.347 \\
$\geq 10^{5}$ & $52(48.6)$ & $53(55.2)$ & & \\
Lactobacilli count & & & & \\
$<10^{5}$ & $59(61.5)$ & $60(52.2)$ & 1.834 & 0.176 \\
$\geq 10^{5}$ & $37(38.5)$ & $55(47.8)$ & & \\
\hline
\end{tabular}

Level of significance ( $p$ value)

42 (16.6\%) needed sealant applications, 33 (13\%) needed one surface filling, 49 (19.4\%) needed two surface fillings, $23(9.1 \%)$ needed pulp therapy, 8 (3.2\%) needed extraction, and $16(6.3 \%)$ needed malocclusion correction (Graph 2$)$.

\section{DISCUSSION}

The main purpose of this study was to identify risk factors and treatment needs among orphan children of Selangor, Kuala Lumpur, Malaysia. As oral health is an integral part of general health, oral diseases affect various aspects of the quality-of-life. Children who lead their life without parents either due to death or leaving because of parent incapability to bring up are called orphans. ${ }^{6}$ Orphans lack the love, affection, and warmth of a natural

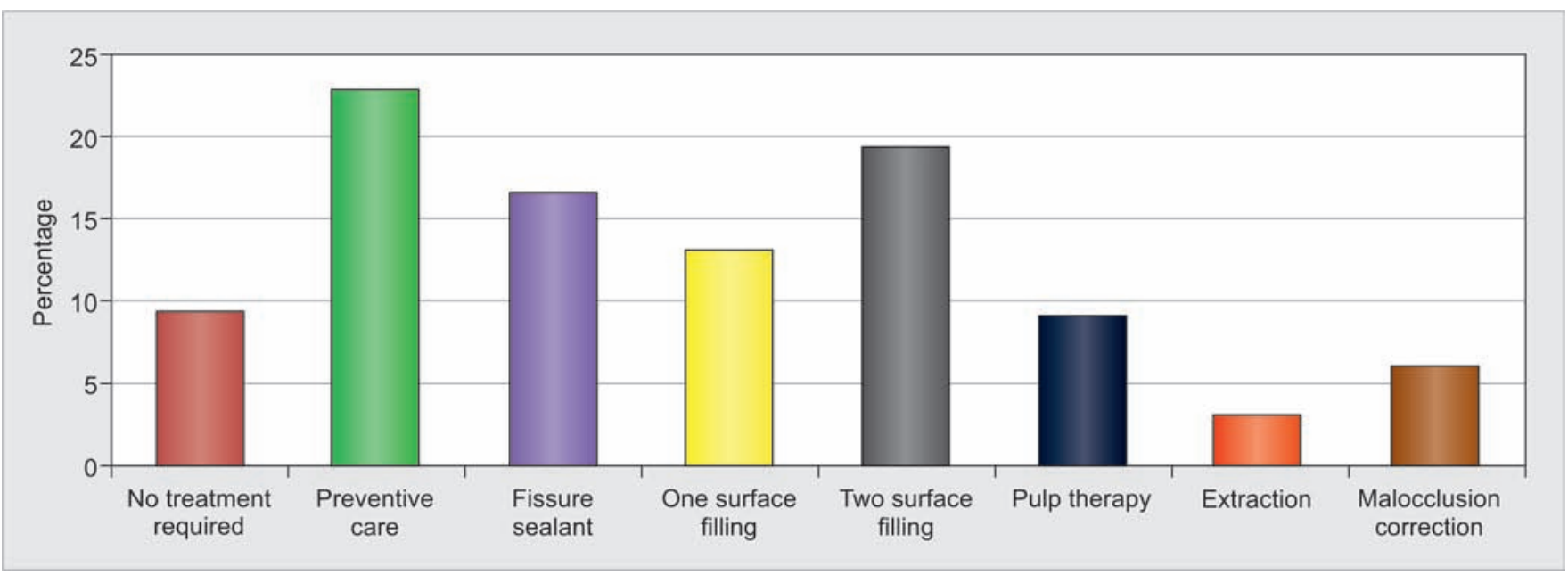

Graph 2: Treatment needs in study group 
family environment. Children living in orphanages, due to absence of parental care and support, may lack basic knowledge to maintain oral health.

Dietary habits have shifted in recent decades and have been associated with increased risk of disease, such as dental caries, type II diabetes, and obesity. More than 30\% of the child's diet was reported to come from a variety of snacking foods, such as candies, cookies, potato chips, fried potatoes, and soft drinks. Snacking ${ }^{12}$ has gained an increasing role as a risk indicator for caries development in children. From the results of our study, there were significant correlations between snacking habit and dental caries. Understanding children's eating attitudes is important in terms of their health. Our study was consistent with snacking on sucrose-containing products, as well as starch-containing chips, and the presence of plaque is associated with caries in children living in a low-socioeconomic status, high-caries area in an industrialized country (USA). ${ }^{13}$ In a study by $\mathrm{Alm},{ }^{14}$ unfavorable snacking habits at 1 and 3 years of age were associated with caries approximately at 15 years. This also depends on parent's attitudes to dental health and psychosocial factors during early childhood. A thorough understanding of lifestyle-associated risk factors and healthy snacking remains targets for the prevention of caries in these children. Although the maximum number of children brushed twice in a day, the oral hygiene was poor. Oral hygiene related to caries showed that children with bad oral hygiene had more decayed teeth with bad gingival health status. This shows that maintenance of oral hygiene status plays a major role in maintaining diseasefree tooth. These findings are similar to a study by Gaur et $\mathrm{al}^{15}$ where most of the children $(99.4 \%)$ brushed their teeth only once, while a very small percentage $(0.6 \%)$ brushed twice due to nonavailability of brushing aids (toothbrush and tooth paste), lack of guidance and assistance during brushing, and lack of awareness regarding importance of brushing at night. Good oral health practice $^{16}$ is a must in maintaining oral health and this can be achieved by creating awareness through various professional bodies and integrated school health programs. Similar studies done by Sunayana et $\mathrm{al}^{17}$ showed higher prevalence of dental caries with increasing age due to poor oral hygiene. In the study by Goel et al, ${ }^{18}$ the prevalence of dental caries showed upward trend from $34.3 \%$ (12 years) to $46.5 \%$ (15 years) in children.

The importance of S. mutans and Lactobacilli as human odontopathogens in saliva for the development of dental caries has been extensively reviewed through many crosssectional studies. Sakeenabi and Hiremath ${ }^{19}$ in their study showed $98.47 \%$ of participants carried detectable salivary levels of S. mutans and $87.24 \%$ had salivary Lactobacilli. In our study, $80.2 \%$ carried detectable levels of $S$. mutans and $83.3 \%$ carried detectable Lactobacilli. There was no statistically significant difference between the $S$. mutans and Lactobacilli count between males and females. The high salivary microbial counts in correlation with the cariogenic environment of the study population stress the importance of necessary preventive programs. Loesche ${ }^{20}$ in his research, also proved the age at which colonization of $S$. mutans in plaque is a reliable indicator of subsequent caries activity. Children who harbored S. mutans in their plaque by age 2 developed 10.6 decayed/ missing/filled surface by age 4 . Hence, understanding the ecology of salivary cariogenic microflora allows formulating treatment plans that have a profound effect on the incidence of dental decay in child population.

Orphan children in our study showed decayed components for both primary and permanent teeth comprising a major part of caries experience, whereas missing due to caries and filled component are next. There was poor accessibility to restorative dental care and preventive care among these children. The majority of them needed preventive care followed by fissure sealant, one surface filling, two surface filling, pulp therapy, malocclusion correction, and extractions. Out of 253, only 24 $(9.5 \%)$ showed good oral health care. These figures were compared with the study of Khare et al, ${ }^{21}$ where $26.2 \%$ of participants required one surface filling, 18.3\% required two or more surface fillings, and 5.2\% required extraction of one or more teeth. A study done by Chakravarthy et $\mathrm{al}^{22}$ in the Uttara Kannada district of India, among orphanage children, showed $31 \%$ of pulpal involvement using polyunsaturated fatty acid index and when compared with our study showed 9.1\%. A cross-sectional study was conducted by Pratap et $\mathrm{al}^{23}$ among 200 orphanage children aged 7 to 18 years from randomly selected orphanages in Bengaluru city. Caries experience in primary and permanent dentition was 40.5 and $38 \%$ respectively, which is higher when compared with our study. The limitations of our study are sample size, unequal gender distribution, and no demarcation of deciduous and permanent dentition caries experience and treatment needs.

\section{CONCLUSION}

This study shows that there is a great need for implementing preventive measures among children living under special circumstances. The oral status of the orphans is poor, and this community has experienced a low utilization of preventive or therapeutic oral health services. In future, orphans should be considered as a priority group when formulating plans for oral health care.

\section{ACKNOWLEDGMENTS}

Authors would like to thank all participants who participated in the study, school authorities of Selangor, and 
Dr Aung Ko Ko (Department of Community Medicine, Mahsa University) without whose valuable input, this work would not have been possible.

\section{REFERENCES}

1. McDonald RE, Avery DR, Dean JA. Dentistry for the child and adolescent. 8th ed. St. Louis (MO): Elsevier Mosby; 2004. p. 205.

2. Petersen PE, Bourgeois D, Ogawa H, Estupinan-Day S, Ndiaye C. The global burden of oral diseases and risks to oral health. Bull World Health Organ 2005 Sep;83(9):661-669.

3. Petersen PE. The World Oral Health Report 2003: continuous improvement of oral health in the 21st century-the approach of the WHO global oral health program. Community Dent Oral Epidemiol 2003 Dec;31 (Suppl 1):3-23.

4. The Permanent Committee for Academic Research and Issuing Fatwas, Kingdom of Saudi Arabia. The duration of orphan hood. Fatwa No. 20711 [last updated 2011; last accessed 2012 Apr]. Available from: http://www.alifta.net 3.

5. UNICEF Press Center. Orphans [last updated 2012 May 25; last accessed 2012 Dec]. Available from: http:/ / www.unicef. org/media/media_45279.html.

6. Orphanage. Wikipedia, the Free Encyclopedia.mht [last cited 2009 Dec 12]. Available from: http:/ / www.en.wikipedia.org/ wiki/orphanage.

7. Oral Health Division, Ministry of Health Malaysia. National Oral Health Survey of School Children (NOHSS 2007); 2007.

8. Naidu R, Prevatt I, Simeon D. The oral health and treatment needs of school children in Trinidad and Tobago: finding of a national survey. Int J Paediatr Dent 2006 Nov;16(6):412-418.

9. Pieper K, Dirks B, Kessler P. Caries, oral hygiene and periodontal disease in handicapped adults. Community Dent Oral Epidemiol 1986 Feb;14(1):28-30.

10. James GA, Brumley DE, Blackford JU. Community socioeconomic status and children's dental health. J Am Dent Assoc 2001 Feb;132(2):216-222.

11. World Health Organization. Oral health survey: basic methods. 4th ed. Geneva: World Health Organization; 1997. p. 26-29.

12. Johansson I, Holgerson PL, Kressin NR, Nunn ME, Tanner AC. Snacking habits and caries in young children. Caries Res 2010;44(5):421-430.
13. Kressin NR, Nunn ME, Singh $H$, Orner MB, Pbert L, Hayes C, Culler C, Glicken SR, Palfrey S, Geltman PL, et al. Pediatric clinicians can help reduce rates of early childhood caries: effects of a practice-based intervention. Med Care 2009 Nov;47(11): 1121-1128.

14. Alm A. On dental caries and caries-related factors in children and teenagers. Swed Dent J Suppl 2008;(195):7-63.

15. Gaur A, Sujan SG, Katna V. The oral health status of institutionalized children that is, juvenile home and orphanage home run by Gujarat state government, in Vadodara city with that of normal school children. J Indian Soc Pedod Prev Dent 2014 Jul-Sep;32(3):231-237.

16. Sharma A, Gaur A, Pareek S, Raja V, Sanadhya S, Sharma AB. Oral health status and treatment needs among orphanage children of Jaipur city. Sch J Appl Med Sci 2014;2(5D): 1776-1780.

17. Sunayana G, John J, Saravanan S, Arumugham IM. Prevalence of dental caries among 12 and 15 years old school children in Chennai city. J Indian Soc Pedod Prev Dent 2005;13:17-22.

18. Goel R, Vedi A, Veeresha KL, Sogi GM, Gambhir RS. Oral hygiene practices and dental caries prevalence among 12 and 15 years school children in Ambala, Haryana-a cross-sectional study. J Clin Exp Dent 2015 Jul 1;7(3):e374-e379.

19. Sakeenabi B, Hiremath SS. Dental caries experience and salivary Streptococcus mutans, Lactobacilli scores, salivary flow rate, and salivary buffering capacity among 6-year-old Indian school children. J Int Soc Prev Community Dent 2011 Jul;1(2):45-51.

20. Loesche W. Role of Streptococcus mutans in human dental decay. Microbiol Rev 1986 Dec;50(4):353-380.

21. Khare V, Koshy A, Rani PJ, Srilatha S, Sonam-Kapsc C, Agrawal A. Prevalence of dental caries and treatment needs among the orphan children and adolescents of Udaipur district, Rajasthan, India. Contemp Dent Pract 2012 Mar 1;13(2):182-187.

22. Chakravarthy PK, Shashidhar A, Kumar YS. Unmet restorative needs among orphanage children of Uttara Kannada district. J Educ Ethics Dent 2014;4(2):65-68.

23. Pratap R, Manjunath PP, Uma SR. Caries experience and its relationship with oral health related quality of life among orphanage children of Bengaluru city: a cross-sectional study. Indian Assoc Public Health Dent 2016;14(4):397-402. 